\title{
Least-Squares Seasonally Adjusted Unemployment Data
}

President Roosevelt hoped that shifting Thanksgiving from the last to the fourth Thursday of November would stimulate the 1939 economy by lengthening the Christmas shopping season. The measure stimulated more debate than employment.

Ordinarily, techniques of seasonal adjustment escape controversy. Except in recession, business analysts and econometricians are inclined to accept seasonally adjusted figures without question. Only in slack times is each monthly pip of the unemployment rate awaited with keen anticipation. Regrettably, it is precisely in these times that technical problems in seasonally adjusting the unemployment rate become particularly acute. While the distortions are short-lived inasmuch as the annual average is insensitive to the particular procedure used in seasonally adjusting the data, they can befuddle the analyst attempting to identify the cycle's lower turning point. This paper presents a least-squares alternative to the official method for seasonally adjusting the unemployment rate.

In the summer of 1975, the Bureau of Labor Statistics discounted in advance the decline expected to be posted for June because of overadjustment stemming from the entrance of students into the labor force. The warning of Julius Shiskin, the commissioner of BLS, was quoted in the New York Times: "If you see a sharp drop [in June], defer your celebration

Note: The research reported in this paper was supported by Wesleyan University. All computations were executed on the Wesleyan DEC-10 computer. I am indebted to Michael Wiater for assistance in preparing the data for processing. 
until you see the July figures." ${ }^{\prime 1}$ In testimony before the Joint Economic Committee, Commissioner Shiskin had explained that the multiplicative BLS method assumes that the seasonal movement is proportional to the level of the series; the June 1975 figure would be adjusted by a multiplicative factor determined the preceding January (for example, unemployment of male teenagers in June would be obtained by dividing the raw figure by the adjustment factor 1.402). Shiskin predicted that overcorrection would occur because the number of young people entering the labor market in June would not be proportionate to the exceptionally high levels of unemployment. He went on to explain that the seasonal factors are announced at the beginning of each calendar year: "I feel locked in. . . I I think we have to sweat out the year with the seasonal factors we have."' The relevant data, together with some alternative estimates using the Census Bureau's $\mathrm{X}-11$ method, are recorded in table 1 . The revisions, released in February 1976, indicate that unemployment had peaked in May, but the June decline was only 0.2 percentage point, rather than the originally reported 0.6 point. The erratic October surge of 0.3 point, so disconcerting at the time, is eliminated in the revised series. The latest revisions incorporate a major modification of earlier BLS procedures. ${ }^{3}$ They involve an additive adjustment for teenage unemployment while retaining a multiplicative adjustment for other categories, including teenage employment; for example, the June 1976 adjustment figure for teenage male unemployment will be obtained by subtracting 283,000 from the raw figure, while the adjusted figure for teenage nonagricultural male employment for that month will be obtained by dividing the raw employment figure by $1.14 .^{4}$

The seasonal-adjustment factor is sensitive to the type of aggregation used and to the method of adjustment. The official unemployment rate is calculated by applying the Census X-11 program to twelve component

1. New York Times, June 18, 1975.

2. Testimony of June 6,1975, in Employment-Unemployment, Hearings before the Joint Economic Committee, 94:1 (Government Printing Office, 1975), pt. 5, p. 802. The adjustment factor that I have cited comes from Employment and Earnings, vol. 21 (February 1975), p. 9.

3. For a brief discussion of the new procedure, see Thomas J. Plewes, "Revision of Seasonally Adjusted Labor Force Series," Employment and Earnings, vol. 22 (February 1976), pp. 7-9. The new revisions were carried back to 1970. The earlier data were adjusted by the BLS seasonal-factor method. See also John F. Early and Paul O. Flaim, "Statistical Characteristics of Major BLS Series," Monthly Labor Review, vol. 97 (July 1974), pp. 48-52.

4. Employment and Earnings (February 1976), p. 10. 


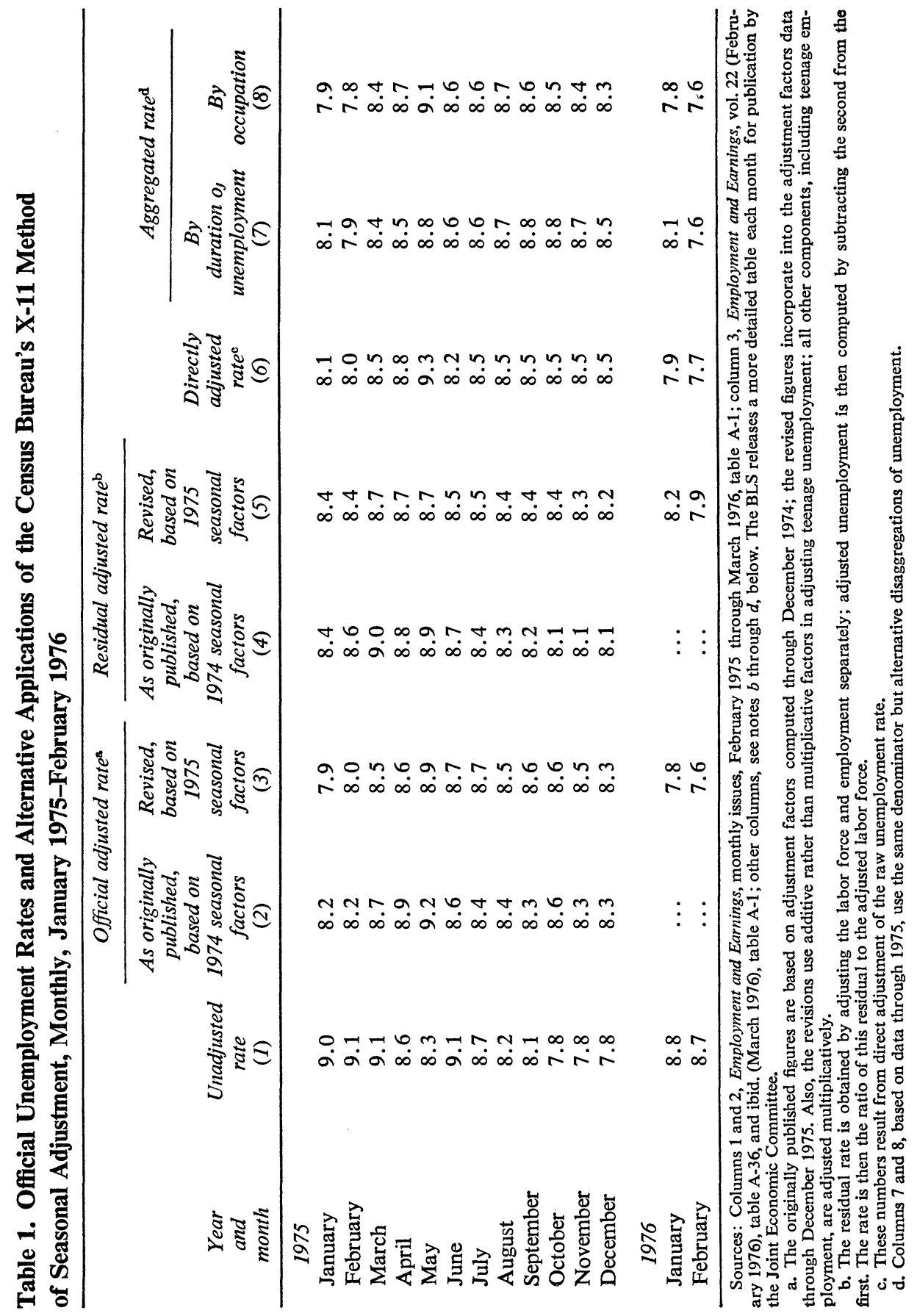


series: four unemployment series based on an age and sex breakdown; and eight employment series, again based on age and sex, with a further subdivision into agricultural and nonagricultural components for independent adjustment. The four adjusted unemployment series and eight adjusted employment series are added to yield the BLS adjusted total labor force. Alternative disaggregations, such as those shown in table 1 , can yield very different results. The official BLS seasonally adjusted unemployment rate for January 1976 is 7.8 percent; disaggregation by duration of unemployment yields an 8.1 percent rate. According to the residual methodsubtracting BLS adjusted employment from BLS adjusted labor force-the rate was 8.2 percent, unchanged from December 1975. As another alternative, if all categories are adjusted with the additive procedure, the unemployment rate is also unchanged at 8.2 percent.

These problems of seasonal adjustment are not new, although they seem to be particularly severe currently. Their effect is comparable to that of sampling error, which is estimated by the BLS to be 0.11 percent for month-to-month changes. ${ }^{5}$

I believe that these recurrent difficulties may be resolved by replacing the Census X-11 program, possibly with a refinement of the least-squares method explored in this paper.

Table 2 contrasts the official BLS seasonally adjusted unemployment rate with my least-squares seasonally adjusted series. Certain properties of my procedure are explored in the next section. Of special interest is its sumpreserving nature, which means that the adjusted rate is unaffected by disaggregation. Mine is a mixed additive-multiplicative procedure, the blend being determined by the data. The following sections will provide first a rationale for seasonal adjustment and then a review of problems in modeling seasonal forces. Certain implications of the analysis are considered in the concluding section.

\section{The Least-Squares Adjustment Procedure}

The essential features of my least-squares seasonal-adjustment procedure were described in a theoretical article I published in $1963,{ }^{6}$ but the

5. This is the figure traditionally reported in table $\mathrm{E}$ of the appendix of Employment and Earnings-for example, vol. 21 (June 1975), p. 134. In fact, the standard error depends upon the level of the unemployment rate; the standard error is 0.11 percent when the unemployment rate is 5 percent but rises to 0.14 percent when the unemployment rate is 8.9 percent.

6. Michael C. Lovell, "Seasonal Adjustment of Economic Time Series and Multiple 
present paper reports the first empirical application. The procedure has a number of desirable properties.

First, the method assures sum preservation-that is, series that sum in unadjusted form will also sum after seasonal adjustment. Adjusting the number of unemployed with a sum-preserving procedure gives the same results as subtracting seasonally adjusted employment from the adjusted labor force. Confusion is avoided because the unemployment rate obtained by applying the "residual" method to data on the labor force and employment adjusted by least squares is identical to that obtained from such data on unemployment and employment. When convenient, component series can be adjusted by least squares and then summed; but in contrast to the BLS procedure, precisely the same results will be obtained by processing the aggregate. Also, sum preservation seems a particularly useful property when adjusting flow-of-funds data and other financial and business time series.

The second advantage of the method lies in its orthogonality. With an orthogonal adjustment procedure, the seasonal component obtained by subtracting the unadjusted from the adjusted data is uncorrelated with the adjusted series. The implication is that no seasonality remains in the data. This will not be true of an adjustment that is not statistically orthogonal. ${ }^{7}$

Third, the proposed method is idempotent. A time series adjusted by a procedure that does not have this characteristic will be disturbed if reprocessed by the same seasonal-adjustment procedure. Thus, nonidempotent procedures are unsatisfactory either because some seasonal is left in the series or because they distort a series that has already been purged of seasonality. Reprocessing data adjusted with an idempotent procedure will not affect the adjusted series.

In my 1963 article I demonstrated that a sizable family of seasonaladjustment strategies satisfies these three requirements. I showed that the least-squares method can be applied so as to execute any seasonal-adjustment procedure that is sum preserving, orthogonal, and idempotent. This does not mean that any adjustment technique satisfying these requirements must be executed by the least-squares method, only that it can be. Nor does

Regression Analysis," Journal of the American Statistical Association, vol. 58 (December 1963), pp. 993-1010; reprinted in Arnold Zellner, ed., Readings in Economic Statistics and Econometrics (Little, Brown, 1968).

7. This criterion was discussed by John A. Brittain, "A Bias in the Seasonally Adjusted Unemployment Series and a Suggested Alternative," Review of Economics and Statistics, vol. 44 (November 1959), pp. 408-09. 
it imply that other regression adjustment procedures, such as those considered at Census and the BLS, are sum preserving, orthogonal, and idempotent.

While sum preservation is obviously desirable from the viewpoint of consistency, an adjustment technique that simultaneously preserves both sums and products would be advantageous. Running a sum-preserving procedure in the logs will preserve products but not sums. Sum- and product-preserving methods should not be confused with multiplicative and additive adjustments: additive adjustments do not necessarily preserve sums and multiplicative procedures need not preserve products. In my earlier paper I demonstrated that no nontrivial adjustment technique preserves both sums and products. The results presented below reveal that adjusting the raw unemployment rate directly yields figures similar to those obtained by computing the ratio of least-squares-adjusted unemployment to least-squares-adjusted labor force. By far the biggest discrepancies between the two occur in 1975.

\section{Rationale}

A two-step application of the principle of division of labor is frequently relied upon when seasonality is encountered. First, the seasonal element is removed from the data. Then, an econometrician may seek to explain the resulting series in terms of an explicit causal model. In much the same vein, business analysts, when analyzing current economic conditions and projecting future developments, find it convenient to work with data from which seasonal forces have been extracted. Yet seasonal adjustment is traditionally characterized as the problem of decomposing the observed time series into trend-cycle, seasonal, and irregular components. ${ }^{8}$ Neither

8. The spectral strategy assumes that the trend component has already been removed from the data. D. M. Grether and M. Nerlove argue that the desirability of alternative techniques of seasonal adjustment can be adequately assessed only in the time, rather than the frequency, domain; nonetheless, they invoke the traditional assumption that the time series is the product of trend-cycle, seasonal, and irregular components. See their paper, "Some Properties of 'Optimal' Seasonal Adjustment," Econometrica, vol. 38 (September 1970), pp. 682-703. The moving-average procedure first removes trend although the process may be iterated in order that a refined trend can be extracted with the aid of first-round estimates of the seasonal component. The same trichotomy underlies the regression approach of Dale W. Jorgenson, "Minimum Variance, Linear, Unbiased Seasonal Adjustment of Economic Time Series," Journal of the American 
business analysts nor econometricians are likely to regard their data as having been generated in this way. Business analysts are all too aware of the multitude of interacting forces determining the movement of economic time series; and the trend-cycle-seasonal-irregular trichotomy is alien to the traditional causal models underlying econometric research.

A quite different rationale underlies the least-squares seasonal-adjustment procedure, and supports the consistent division of labor. Suppose that the time series of interest $(Y)$ is generated by a traditional linear model in which the explanatory variables have been partitioned into a set of economic forces $(X)$ and a set of seasonal forces $(S)$ :

$$
Y=\alpha+\beta_{1} X_{1}+\ldots+\beta_{k} X_{k}+\gamma_{1} S_{1}+\ldots+\gamma_{d} S_{d}+\epsilon .
$$

For one example, the raw aggregate unemployment rate, in accordance with Okun's law, can be viewed as the result of the percentage gap between potential and actual output plus seasonal dummy variables. For another, teenage unemployment may result from a variety of economic factors along with a number of "seasonal forces" of lesser interest, such as summer vacations. For a third, adverse weather conditions may cause seasonal unemployment of construction workers in New England. Seasonal adjustment may be conceived of as the task of applying a sum-preserving, orthogonal, idempotent transformation to purge the seasonal, leaving

$$
Y^{a}=\alpha+\beta_{1} X_{1}^{a}+\ldots+\beta_{k} X_{k}^{a}+{ }_{\epsilon}^{a} .
$$

Here the superscript $a$ indicates that the data have been adjusted. In addition to purging the direct effect of the seasonal forces, this expression also deletes the seasonal movement induced by the other variables. This leaves a simpler relationship, unencumbered by complications from seasonal factors, on which the user can focus attention in subsequent analysis. ${ }^{9}$

Statistical Association, vol. 59 (September 1964), pp. 681-724. Jorgenson would remove the trend-cycle and seasonal components simultaneously and then add back in the trend-cycle component; the resulting "adjusted" series is not orthogonal. See also Allan H. Young, "Linear Approximations to the Census and BLS Seasonal Adjustment Methods," Journal of the American Statistical Association, vol. 63 (June 1968), pp. 445-71.

9. This may be easily explained by rewriting equation 1 in matrix notation:

$$
Y=X \beta+S \gamma+\epsilon .
$$

Premultiplying by the matrix

$$
A=I-S\left(S^{\prime} S\right)^{-1} S^{\prime}
$$

yields the desired adjustment. Note that the matrix $A$ is idempotent and that it annihilates the matrix of seasonal factors; that is, $A A=A$ and $A S=0$. We have $A Y=Y-\hat{Y}$, where $\hat{Y}=S c, c=\left(S^{\prime} S\right)^{-1} S^{\prime} Y$ is the $d \times 1$ vector of regression coefficients when $Y$ is regressed on $S$. The procedure generalizes to simultaneous-equation models. 
My least-squares method of seasonal adjustment yields the adjusted time series defined by equation 2 without making explicit use of the first set of explanatory variables in equation 1 . The method achieves seasonal adjustment through the following regression:

$$
Y=a^{\prime}+c_{1}{ }^{\prime} S_{1}+\ldots+c_{d}{ }^{\prime} S_{d}+\epsilon .
$$

The seasonally adjusted series, $Y^{a}$ of equation 2 , is obtained by adding the mean of $Y$ to the residuals of regression equation $3 .{ }^{10}$

\section{Modeling Seasonal Forces}

While the least-squares technique for seasonal adjustment can be applied without a consensus on the precise economic variables that enter into the underlying model of equation 1 , an appropriate set of seasonal variables must be included. ${ }^{11}$ The simple seasonal dummy variables frequently used in regression analysis with unadjusted data are obvious candidates, but this approach does not allow for a moving seasonal; it is equivalent to subtracting for each month the excess of the monthly average over the grand mean. Much may be gained by a more sophisticated specification.

An extended study at Wesleyan University of least-squares seasonaladjustment procedures has resulted in a technique based on the principles just discussed. In table 2, the adjusted monthly unemployment rates for 1975 arrived at using this technique are compared with the officially published unemployment rates. ${ }^{12}$ Both sets of rates are based on data available at the end of 1975 .

10. In my earlier paper I specified the adjustment to be made for lost degrees of freedom, equal to the rank of the matrix $S$, in order to avoid "puffing" the correlation and $t$-statistics of regressions run with seasonally adjusted data. Note that neither equation 2 nor 3 provides precise guidance to the appropriate specification of $S$; in particular, $\boldsymbol{t}$-statistics of regression 3 are no substitute for those generated with the seasonal variables of regression 1 .

11. The variables on the right-hand side of the equation could be polynomials or exponential trends in any application in which they made economic sense (though that is not likely). Models of this sort have been considered by several writers. See, for example, Arne Fisher, "A Brief Note on Seasonal Variation," Journal of Accountancy, vol. 64 (September 1937), pp. 174-99; Dudley J. Cowden, "Moving Seasonal Indexes," Journal of the American Statistical Association, vol. 37 (December 1942), pp. 523-24.

12. The complete time series of adjusted monthly rates from 1949 through 1975 is available from the author on request. 
Table 2. Comparison of Official Adjusted Unemployment Rates and Unemployment Rates Derived by Author's Least-Squares SeasonalAdjustment Procedure, Monthly, 1975

Percent

\begin{tabular}{lcc}
\hline Month & $\begin{array}{c}\text { Official } \\
\text { adjusted rate }\end{array}$ & $\begin{array}{c}\text { Rate derived by } \\
\text { author's procedure }\end{array}$ \\
\hline January & 7.9 & 8.66 \\
February & 8.0 & 8.75 \\
March & 8.5 & 9.02 \\
April & 8.6 & 8.93 \\
May & 8.9 & 8.98 \\
June & 8.7 & 8.38 \\
July & 8.7 & 8.45 \\
August & 8.5 & 8.26 \\
September & 8.6 & 8.16 \\
October & 8.6 & 8.05 \\
November & 8.5 & 7.91 \\
December & 8.3 & 7.92 \\
\hline
\end{tabular}

Sources: Official adjusted rate from table 1, column 3; author's rate is derived from the official raw unemployment rates compiled by the U.S. Bureau of Labor Statistics, using the least-squares procedure described in the text.

The procedure, while relatively simple, allows for a slowly evolving, additive, semimultiplicative seasonal pattern and at the same time equalizes monthly means; twenty-four degrees of freedom were absorbed in adjusting the data. The regression model takes the following form:

$$
Y=\sum c^{\prime}(m)[d(m)]+\sum c^{\prime \prime}(m)\left[d(m) L^{*}\right]+e,
$$

subject to

$$
\sum c^{\prime \prime}(m)=0 .
$$

Here $Y$ is the variable to be deseasonalized (for example, the labor force or unemployment), $L^{*}$ is a simple twelve-month lagging average of the labor force; the $d(m)$ are dummy variables which equal unity in the $m$ th month and zero otherwise, and $c^{\prime}(m)$ and $c^{\prime \prime}(m)$ are adjustment coefficients to be determined by the application of least squares to equation 4 . Thus, for month $m$,

$$
Y_{m}^{a}=\bar{Y}+e=\bar{Y}+\left[Y_{m}-c^{\prime}(m)-c^{\prime \prime}(m) L_{m}^{*}\right]:
$$

The adjusted series may be obtained by adding the residual of equation 4 to the mean of $Y$. This adjustment strategy is only semimultiplicative, regardless of the relative strengths of $c^{\prime}(m)$ and $c^{\prime \prime}(m)$; for example, the 
adjustment of unemployment in June depends upon $c^{\prime}$ (June) and the product of $c^{\prime \prime}(J u n e)$ times the trend level of the labor force in June. ${ }^{13}$

This is a simplistic approach, and though it yields an evolving adjustment that is sum preserving, orthogonal, and idempotent, a number of obvious refinements await evaluation. In my earlier paper I pointed out the possibility of economizing on degrees of freedom when there is a fair degree of continuity from season to season. This condition permits the use of sinusoidal seasonal variables in a more economical representation involving fewer parameters and possibly greater stability as new observations accumulate. While a general-purpose least-squares program may prove satisfactory for a wide range of economic time series, I suspect that, for seasonal adjustment, much will be gained by exploiting the ease with which the least-squares approach allows for the inclusion of explicit seasonal forces. For example, the dummy-variable structure required in seasonally adjusting consumption of domestic heating oil might be greatly simplified by including the number of degree-days as an explicit seasonal variable; indeed, seasonal dummies are proxies for such factors. In the case of unemployment, incorporating monthly data on school enrollment as a specific variable would be particularly useful if the data were readily available. The least-squares approach permits the addition of dummy variables to indicate changes in the date of new-car introductions and such irregular factors as strikes and shifts in the dates of Easter and Thanksgiving.

\section{STABILITY OF ESTIMATES}

Like other techniques of adjustment, such as the alternatives produced by BLS that were shown in table 1, the least-squares technique reveals a disheartening lack of precision. Table 3 compares the least-squares adjustments for 1975 and early 1976 that would have been made at different times in this interval. It also compares the direct adjustment of the unemployment rate with the adjustment available by dividing adjusted unemployment by the adjusted labor force.

13. The procedure resembles in some respects that employed by $\mathbf{J}$. Durbin and M. J. Murphy in an article that was brought to my attention while this paper was undergoing revision. However, their approach does not preserve sums because they use the trend of each individual time series rather than the same trend variable for all the series being adjusted. "Seasonal Adjustment Based on a Mixed Additive-Multiplicative Model," Journal of the Royal Statistical Society, Series A, vol. 138, pt. 3 (1975), pp. 385-410. 
Table 3. Effect of Successive Seasonal Adjustments from Least-Squares Technique, Monthly, 1975 and 1976

Percent

\begin{tabular}{|c|c|c|c|c|c|c|c|c|}
\hline \multirow[b]{2}{*}{$\begin{array}{c}\text { Year } \\
\text { and } \\
\text { month }\end{array}$} & \multicolumn{4}{|c|}{$\begin{array}{c}\text { Unemployment rate calculated as } \\
\text { direct least-squares adjustment } \\
\text { of official raw rates }\end{array}$} & \multicolumn{4}{|c|}{$\begin{array}{c}\text { Unemployment rate calculated as } \\
\text { ratio of least-squares-adjusted } \\
\text { unemployment to least-squares- } \\
\text { adjusted labor force }\end{array}$} \\
\hline & $\begin{array}{l}\text { June } \\
1975\end{array}$ & $\begin{array}{c}\text { Octo- } \\
\text { ber } \\
1975\end{array}$ & $\begin{array}{c}\text { Decem- } \\
\text { ber } \\
1975\end{array}$ & $\begin{array}{c}\text { Febru- } \\
\text { ary } \\
1976\end{array}$ & $\begin{array}{l}\text { June } \\
1975\end{array}$ & $\begin{array}{c}\text { Octo- } \\
\text { ber } \\
1975\end{array}$ & $\begin{array}{c}\text { Decem- } \\
\text { ber } \\
1975\end{array}$ & $\begin{array}{c}\text { Febru- } \\
\text { ary } \\
1976\end{array}$ \\
\hline \multicolumn{9}{|l|}{1975} \\
\hline January & 8.30 & 8.55 & 8.66 & 8.12 & 8.26 & 8.45 & 8.54 & 8.16 \\
\hline February & 8.39 & 8.63 & 8.75 & 8.25 & 8.36 & 8.55 & 8.63 & 8.35 \\
\hline March & 8.66 & 8.90 & 9.02 & 9.13 & 8.65 & 8.83 & 8.91 & 8.71 \\
\hline April & 8.58 & 8.82 & 8.93 & 9.05 & 8.58 & 8.76 & 8.85 & 8.65 \\
\hline May & 8.64 & 8.87 & 8.99 & 9.10 & 8.63 & 8.82 & 8.90 & 8.77 \\
\hline June & 8.03 & 8.26 & 8.37 & 8.49 & 8.21 & 8.40 & 8.49 & 8.67 \\
\hline July & & 8.34 & 8.45 & 8.56 & & 8.44 & 8.53 & 8.75 \\
\hline August & & 8.15 & 8.26 & 8.37 & & 8.26 & 8.34 & 8.53 \\
\hline September & & 8.05 & 8.16 & 8.27 & & 8.11 & 8.19 & 8.38 \\
\hline October & & 7.93 & 8.04 & 8.15 & & 8.03 & 8.11 & 8.31 \\
\hline November & & & 7.91 & 8.02 & & & 7.97 & 8.10 \\
\hline December & & & 7.92 & 8.03 & & & 7.96 & 8.09 \\
\hline \multicolumn{9}{|l|}{1976} \\
\hline January & & & & 7.96 & & & & 8.01 \\
\hline February & & & & 7.77 & & & & 7.87 \\
\hline
\end{tabular}

Source: Derived from least-squares procedures described in text.

a. The months in the column headings indicate the last observation used in estimating the seasonal factors.

The ambiguity in the BLS adjustment, revealed in table 1, arises from problems of aggregation, from revisions, and from the choice of the direct adjustment of the ratio rather than the ratio of adjusted data. My estimates escape the ambiguity arising from aggregation because of sum preservation, but still suffer from the other problems. Much remains to be done.

\section{Implications}

BLS practice is to stick throughout the year with the 144 seasonaladjustment factors announced in the February Employment and Earnings. Because current observations obviously can contribute to improved adjustment, it might be more appropriate to settle on a computer program to be 
run each month as new observations accumulate, thus making a commitment to a particular technique, rather than particular factors, for seasonal adjustment. If revisions cannot be made during the year, avoiding multiplicative adjustment techniques that are hypersensitive to fluctuations in the number of unemployed becomes all the more important. This consideration argues for an additive version of Census X-11, the residual procedure, or a mixed additive-multiplicative regression approach. At one time, indeed, the BLS had a more flexible policy with regard to revisions:

Seasonal factors for the labor force series are updated only once a year. However, the reliability of the seasonal adjustment of these data is under continual review. If at any time it appears that some modification of the seasonal adjustment procedures will produce more accurate seasonally adjusted data, changes in these procedures may be made before the usual up-dating next January. ${ }^{14}$ The appropriate strategy for handling revisions may be more a question of political economy than of statistics.

The problems encountered in seasonally adjusting the unemployment rate have certain econometric implications. Procedures for predicting the revisions that will be made in the official seasonally adjusted unemployment rate might be useful; studies by Zellner and by Theil in predicting revisions with other types of data are suggestive. ${ }^{15}$ Problems in handling the seasonal in unemployment may also distort conclusions reached from econometric analysis. For example, my study of the determinants of the consumer sentiment index may well have soft-pedaled the role of unemployment because it is the preliminary BLS figure rather than the revised one that makes the consumer so sad; if so, the initial figures should have been used throughout the entire regression period. ${ }^{16}$

The potential benefits from better seasonal adjustment are substantial. Improving the precision of economic indicators can aid the fine tuning of economic policy. Eliminating erratic movements could help bolster business confidence at critical points in the business cycle. In the absence of seasonal adjustment, resort is frequently made to comparisons with the

14. "Seasonal Adjustment for Labor Force Series," Employment and Earnings, vol. 18 (February 1972), p. 11.

15. Arnold Zellner, "A Statistical Analysis of Provisional Estimates of Gross National Product and Its Components, of Selected National Income Components, and of Personal Saving," Journal of the American Statistical Association, vol. 53 (March 1958), pp. 54-65; Henri Theil, Applied Economic Forecasting (Rand McNally, 1966).

16. Michael C. Lovell, "Why Was the Consumer Feeling So Sad?" BPEA, 2:1975, pp. 473-79. 
same period of the previous year. If attention had focused on movements in seasonally adjusted auto sales last year, consumer confidence would have been spared the blows of repeated statements concerning the 30 percent-plus declines from the corresponding week of the preceding year. Business decisions may be sharpened when firms become accustomed to seasonally adjusting their sales data rather than using these over-the-year comparisons.

The least-squares procedure described in this paper is but one of a variety of techniques of seasonal adjustment showing sufficient promise to warrant further study. The NBER-Census Conference on Seasonal Analysis, rescheduled for September 1976, is serving to interest a number of academic researchers in the problem. Perhaps better procedures will be available before the next recession. In the interim, I believe that the BLS should make clear the imprecision involved by reporting interval rather than point estimates; for example, instead of 8.2 percent, the BLS should give the unemployment rate as 8.2 percent plus or minus 0.3 . By the same token, error bars, or bands, rather than lines should be used to present seasonally adjusted data. 


\author{
JOHN F. EARLY \\ Bureau of Labor Statistics
}

\title{
Comment
}

EFFECTIVE in January 1976, the U.S. Bureau of Labor Statistics revised its approach to the seasonal adjustment of unemployment. Unemployment for adults is adjusted using the multiplicative procedures of the X-11 seasonal-adjustment program and unemployment for teenagers is adjusted using the additive procedures of the program. Previously, the multiplicative adjustment was used for all groups.

The multiplicative adjustment assumes that the seasonal component is proportional to the level of the series; the additive adjustment assumes that it is a constant amount from one year to the next and is independent of the level of the series. The new adjustment procedure was adopted after testing the additive and multiplicative hypotheses in two ways: (a) by applying analysis of variance to the ratios and differences of the original series to the trend-cycle; and (b) by regressing the seasonal component against the trendcycle by month to determine whether the intercept (additive) or the slope (multiplicative) was significant.

BLS also tested the "residual" method, in which the labor force and employment are independently adjusted and the difference between them taken as seasonally adjusted unemployment. This method was rejected for four reasons. First, it exhibited more evidence of residual seasonality. Second, it was more erratic. Third, the error of adjustment is proportional to the sampling error in the original series; as a result, twice as much error arises from that source in residual adjustment as it does in the direct methods. Finally, because stable ratios of large, slowly changing numbers approximate constant values, this procedure does not really capture the clearly multiplicative component. ${ }^{1}$

1. A draft technical paper, "Tests of Alternative Seasonal Adjustment Methods: Observations and Recommendations" (1976; processed), in which these studies are discussed in more detail, is available from BLS. 


\section{Epistemology of Seasonal-Adjustment Models}

Linear regression models are generally neat and quite tractable, but there is no special reason to believe that the real world is so clearly linear. At the same time, there is no special reason to believe that the real world derives from trend-cycles, irregulars, and seasonal factors. Both are models to aid understanding, and the choice between them should be made not on prior grounds but rather on the usability of the results. The X-11 approach has had a long and useful history and, as in the case at hand, has been readily adapted to changing seasonal conditions. On the other hand, attempts at regression adjustment, including extensive testing by Harry Rosenblatt at the Census Bureau, have not yet achieved the generality, exactness of fit, and ease of application required of general-purpose adjustment procedures.

\section{Criteria for Adjustment}

Michael Lovell has laid down three criteria for an adequate adjustment and I would like to comment on each:

1. Sum preservation is certainly a nice feature, but I consider it quite secondary. The accuracy of the adjustment certainly comes first.

2. Orthogonality is a highly desirable quality and I think that the final results of several different methods should be given ex-post tests of their actual orthogonality.

3. Idempotency should again be tested on the live data of regression results. BLS used a test for it in arriving at its latest procedures. Final aggregate series all were subjected to a further run of X-11. Only the residual method gave measurable evidence of perturbation of the adjusted series.

Four additional criteria should also be considered in evaluating any new adjustment methodology:

1. The addition of more observations should bring minimal revisions to the previously adjusted data. Lovell's data from table 3 show that the addition of eight months of data produced revisions in the unemployment rate averaging nearly 0.4 point for the first six months of 1975 . The BLS revision averaged less than 0.2 point for the same period.

2. Accurate year-ahead factors are needed for an operating current-statistics program. For years BLS has followed that policy and the 1972 article 


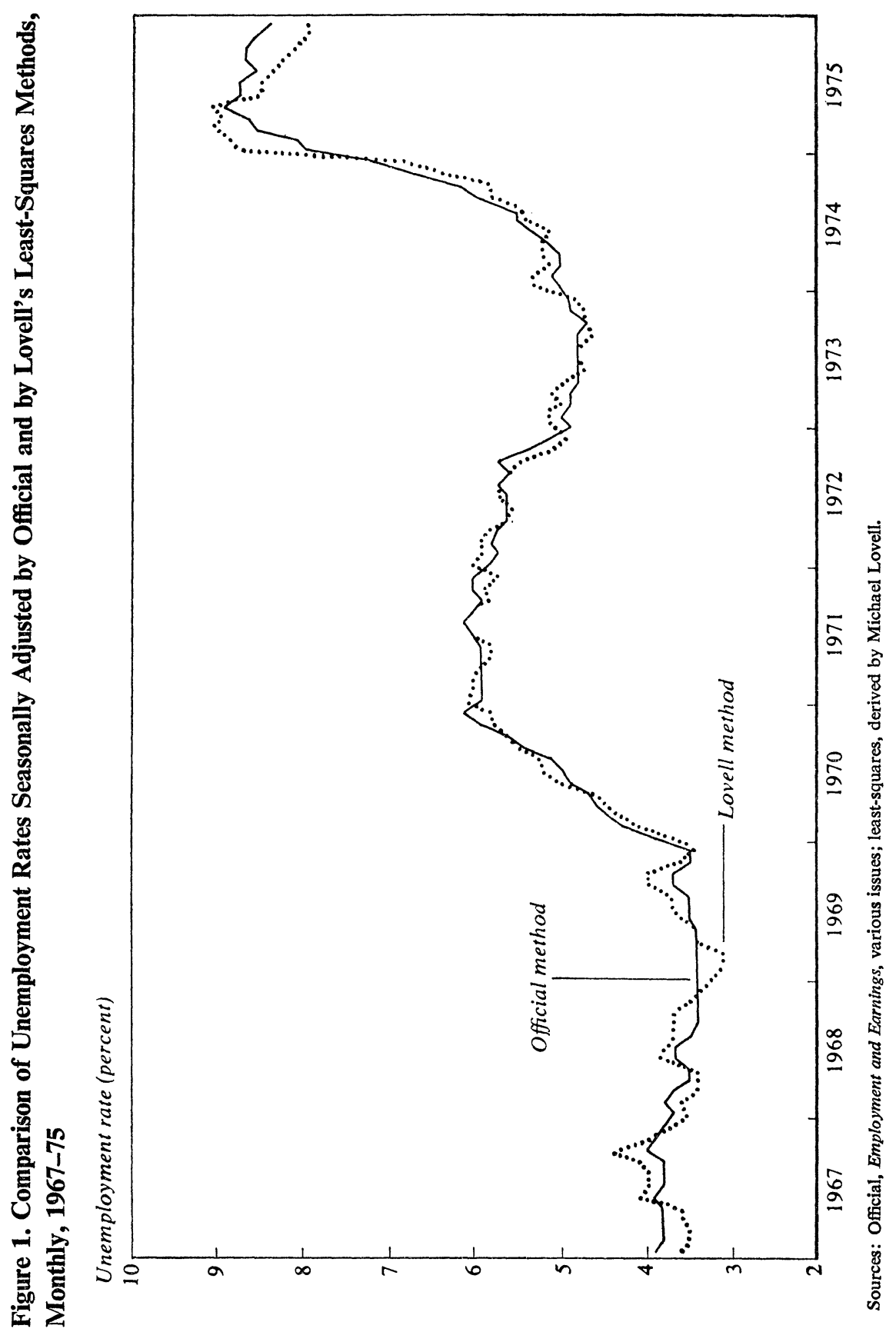


in Employment and Earnings that Lovell cited was simply an acknowledgment that BLS was engaged in research on the best adjustment method, not an announcement that it might be changing the seasonal factor on a monthly basis. Quite aside from the policy preference for advance announcement of factors, two practical matters virtually require the use of year-ahead factors: (a) the adjustment of thousands of series monthly would require excessive staff and computer time and would clearly obstruct the timely release of the data; and (b) the constant revisions of the historical data would be a nightmare for both the producing agency and the users.

3. Any procedure should be subject to fairly quick and easy routine application.

4. Although the real world is unlikely to be smooth and continuous, if other criteria lend no special advantage to some method, a smooth one provides analytical advantages. The average absolute month-to-month change in the seasonally adjusted unemployment rate as published by BLS is 0.12 , giving a slight smoothness advantage over the change of 0.14 when the adjustment is made using Lovell's method. Figure 1 illustrates the somewhat more erratic nature of Lovell's regression method.

\section{Other Specific Comments}

In closing, I wish to make the following points:

First, Lovell's model for adjusting unemployment is additive-that is, the magnitude of the seasonal is independent of the level of the series. (The inclusion of the labor force reflects only long-term trends.) If the BLS results are correct, then for the adult portion of unemployment the model is misspecified. This fact also explains the difference in timing, since the March 1975 peak in unemployment occurred in both the Lovell and X-11 additive results, as opposed to the May peak in the official series.

Second, multiplicative adjustment is "hypersensitive" only if the proper model is additive.

Third, the problems of revisions in seasonally adjusted data as observations accumulate is with us, irrespective of the method. I suspect that "consumer sentiment" is affected more by the "real" unemployment rate than by whatever BLS or anyone else may say it is.

Fourth, the use of explicit seasonal variables in a system of estimated equations is probably appropriate, no matter what the adjustment method, if the aim is to capture the total relationship between variables. 
Fifth, I fully agree that over-the-year comparisons are exceedingly poor substitutes for seasonally adjusted data.

Sixth, while the use of dummy variables for calendar changes such as Easter may be valuable, the use of degree-days or similar adjustments goes beyond seasonal adjustment to a more causative explanatory model.

Seventh, an additional test of any proposed method of seasonal adjustment is the relative accuracy with which the method reproduces the components of an artificially constructed series.

Finally, a practitioner of any new method must evaluate the impact of extreme observations and decide how to deal with them. In estimation by ordinary least squares the effect of extremes is proportional to the square of their deviation, while in the X-11 program their effect is reduced by identification and weighting.

\section{Discussion}

CHRISTOPHER SIMS and several other participants supported Lovell's suggestion that standard errors reflecting both seasonal adjustment and sampling uncertainties be published along with the unemployment statistics. Sims further pointed out that the calculation of standard errors on the seasonal adjustment would require an explicit stochastic model of how the series were generated. Lacking agreement on such a model, the adjusted series and standard errors calculated from a number of alternative models of the process should be made available to users of the statistics.

Sims also noted that an explicit model was needed to decide among different procedures for seasonal adjustment and that the fact that a procedure possessed some intuitively appealing properties was not a reliable basis for choosing it. The method that provided the smoothest series, for example, would take out too much variation by other criteria. In looking for residual seasonality by one method after first adjusting the series by another, one would be likely to find some even if the original adjustment were the appropriate one. Robert Solow added that the causal model underlying most present techniques of seasonal adjustment was implausible. These models 